\title{
CASOS CURIOSOS, PECULIARIDADES Y FORMAS ALTERNATIVAS DE ANOTAR LA MÚSICA EN EL ÁREA HISPÁNICA EN EL SIGLO XVII. PROCESOS DE INTERCAMBIO ENTRE LO CULTO Y LO POPULAR
}

\author{
Dr. Antonio Ezquerro Esteban \\ Departamento de Musicología, CSIC (Barcelona)
}

\begin{abstract}
The present paper deals with an approach to some cases on Spanish $17^{\text {th }}$ century Music notated in a wide variety of forms. The graphic image of these cases, will help us to better understand the adopted shapes of music, in order to reach a better "circulation" among the chapel masters and composers of the period. And that concerns not only to music, but also to the accompanying poems, or other "working models" in further elaborations, such as musical incipits, etc. Then, this contribution goes to think about on the strong influence of the Catholic church -as main patron of music in Spain- on the conformed traditions and customs of Hispanic composition, as well as on the repertories, and how these "manners" conditioned peculiar ways of notating music, creating a big variety of manuscript copies. And last but not least, the paper studies possible interchanges between the "cultivated" and "popular" surroundings of music, trough an blurred round trip, that it is needed, again, to clarify today.
\end{abstract}

\section{Resumen}

El presente artículo pretende realizar una aproximación a algunos casos de música hispana del siglo XVII anotada de las formas más variadas, no por poco frecuentes, menos importantes. Se presenta la imagen "gráfica" de algunas de las múltiples vías que la música de la época llegó a adoptar para "circular" libremente entre los maestros de capilla y compositores (y no sólo la música, sino los textos que la debían acompañar, u otros patrones de trabajo y elaboración posterior, como sus incipits musicales, etc.). Se reflexiona brevemente sobre el enorme influjo del mecenazgo eclesiástico sobre las tradiciones y "costumbres" de composición hispanas, así como sobre los repertorios, y cómo estos "modos de hacer", condicionaron peculiares formas de anotar la música hispánica en una gran variedad de copias manuscritas. Por último, se abordan en este contexto posibles intercambios entre el entorno musical "culto" y el "popular", en un desdibujado camino de ida y vuelta que hoy es preciso nuevamente rastrear.

Es bien conocido que la copia "a papeles", es decir, en un papel o cuadernillo manuscrito para cada parte vocal e instrumental, fue el modo más habitual de copia entre los compositores del ámbito hispánico del siglo XVII, y aun posterior. Y también son conocidas algunas particularidades de las denominadas tabulas compositorias ${ }^{1}$. Pero, aparte de las porcentualmente poco

1. Cfr. -Antonio Ezquerro: "Ideas para desarrollar: cuestiones en torno a la formación de los archivos musicales eclesiásticos en España", en AEDOM Boletín de la Asociación Española de Documentación Musical, IV/1, (1997), pp.5-70. -Id.: "Tabula compositoria, partitura, chapa y borrador. Formas de anotar la polifonía y música instrumental en el ámbito hispánico durante el período barroco", en Festschrift Gertraut Haberkamp zum 65. Geburtstag, Regensburg, 2001 (en prensa). 
relevantes obras musicales dispuestas en partitura de nuestro Seiscientos, o de aquellas otras en su disposición habitual "a papeles", existían otros muchos modos de anotar la música en la época ${ }^{2}$.

Las más frecuentes, las copias en cantoral (en disposición "de atril"), algunas tabulaturas instrumentales "en cifra" (de particular incidencia en el ámbito hispánico en lo referido a la música para tecla o para cuerda pulsada o pinzada), o las copias en "libretes" (cuadernillos independientes para cada voz o instrumento, en donde se recogían, a modo de colección, obras misceláneas o grupos de composiciones (todo un Oficio de difuntos, o una salmodia, p.ej.), del mismo autor o de autores diferentes, anotadas unas a continuación de otras.

Las cinco modalidades de copia mencionadas (partitura, papeles sueltos, cantorales anotados en disposición de atril, libretes, y tabulaturas en cifra), podían darse tanto en forma impresa como manuscrita. Pero, para el caso de la copia manuscrita, en el ámbito hispánico de la época se recogieron, excepcionalmente, otras muchas composiciones musicales, de las formas más variadas. Sabemos, cómo muchas obras se anotaban directamente sobre tabla (en la denominada "tabula compositoria" de que nos hablaba el teórico Pedro Cerone, y de la cual se conservan algunos ejemplares en el Archivo de Música de las Catedrales de Zaragoza) ${ }^{3}$, y luego se borraban. Sin duda, por esa razón se habrán perdido numerosas composiciones, particularmente en el caso de las obras realizadas por los examinandos para sus exámenes de oposición a plazas musicales en capillas eclesiásticas de toda la península ibérica y Latinoamérica.

Pero además, contamos con algunos otros ejemplos, peculiares, curiosos, e incluso en algunos casos, excepcionales, que hoy nos acarrean serios problemas a la hora de abordar su catalogación y estudio crítico. Veámoslos a continuación.

1.- Copias "de archivo". Se trata de copias manuscritas de buena calidad, "sacadas" expresamente para ser custodiadas y bien conservadas en el archivo de música catedralicio, por la importancia de las composiciones anotadas, con vistas a que dichas copias sirvieran como modelo para, a su vez, sacar otras copias más prácticas y no necesariamente tan cuidadas, para su uso frecuente.

Éste es el caso, excepcional, del Símbolo de San Atanasio "Quicumque"4 del maestro Urbán de Vargas (*1606; †1656), obra que le fue encargada en 1651 por el racionero del cabildo metropolitano de La Seo de Zaragoza, D. Juan de Arruego, para que fuera cantada a perpetuidad todos los domingos del año, y en particular el día de la Santísima Trinidad ${ }^{5}$. Semejante obra -el

2. Vid. -Ramón Pelinski: "La polifonía vocal española del siglo XVII y sus formas de escribirla", en Anuario Musical, XXIV (1969) [1970], pp.191-198. [Traducción resumida de su tesis doctoral, Die weltliche Vokalmusik Spaniens am Anfang des 17. Jahrhunderts: der Cancionero Claudio de la Sablonara. Tutzing, "Münchner Veröffentlichungen zur Musikgeschichte, XX", Hans Schneider, 1971].

3. Vid.: -Antonio Ezquerro: "Tabula compositoria, partitura, chapa...", op. cit.

4. Se trata de una obra de enorme importancia teológica, y litúrgica, nada menos que del texto del credo de la fe católica, atribuido erróneamente a San Atanasio de Alejandría, el cual toma su nombre de su comienzo literario "Quicumque vult salvus esse, ante omnia opus est ut teneat catholicam fidem...".

5. Sorprende, que para esa fecha, Vargas (que había sido anteriormente maestro de capilla de la vecina y rival iglesia catedral de El Pilar de la misma ciudad de Zaragoza, adonde volvería años más tarde), era canónigo maestro de capilla de 
Credo- era tan importante, máxime en un tiempo de ascenso de otras confesiones en Europa ${ }^{6}$, que únicamente se rezaba o semitonaba, de modo que no se conoce, al menos en ámbito hispánico, ninguna otra musicalización polifónica de dicho texto. Pues bien, dicha obra, que se conserva en doce libretes en papel, manuscritos cuidadosamente y encuadernados en pergamino, para su ejecución práctica, cuenta además con una copia "de archivo", que hace las veces de "original": un libro (E: $Z a c, \mathrm{LS}-19)^{7}$, asimismo encuadernado en pergamino y copiado con esmero, que se guarda en excelente estado de conservación. En él, se anotan, una a continuación de otra, cada una de las doce partes intervinientes (once voces, más el órgano), a modo de papeles sueltos, de modo que al término de cada voz se dejan algunos folios en blanco antes de que comience la siguiente $\mathrm{voz}^{8}$.

¿Qué tenemos ahí, entonces... una partitura? Evidentemente, no, puesto que no se encuentran las voces dispuestas todas juntas, unas encima de otras, de suerte que de un simple vistazo

la Catedral de Burgos. No deja de ser curioso que un sacerdote de la principal iglesia aragonesa (la catedral metropolitana de "La Seo", donde los monarcas debían jurar y acatar sus leyes y fueros), la cual tenía por entonces su propio y excelente maestro de capilla (el reputado maestro portugués Fray Manuel Correa, tan admirado por Felipe IV), encargara esta obra tan fuera de lo normal a un maestro, aunque conocido (pues había sido poco antes maestro de capilla de la otra catedral zaragozana, entonces en ascenso, "El Pilar"), a la sazón empleado en el (aunque unido por parentesco real a Aragón desde tiempo de los Reyes Católicos, y aliado), "otro" reino, de Castilla, y con antecedentes en la iglesia "rival" de la misma ciudad aragonesa. Sin duda, en el encargo de una obra tan crucial para la liturgia y la fe católica, y en semejantes condiciones (al menos las referidas a lejanía), debió de pesar no poco la gran reputación del maestro Vargas.

6. Recordemos que en 1492 se había expulsado de España a los judíos, y en 1610 a los moriscos. La uniformidad religiosa católica se imponía poco a poco en los reinos hispanos, con el impulso de la propia Iglesia, y de la monarquía. Entretanto, la Reforma Protestante iniciada por Lutero se extendía por toda Europa, con múltiples ramificaciones, algunas de las cuales también alcanzaron la península ibérica, a pesar de que el espíritu contrarreformista hispano supo atajarlas con todos los medios a su alcance. En esta línea, la música de las capillas eclesiásticas hispanas se encaminaba en buena parte a "reafirmar" la diferencia, los signos ya no tan solo propiamente cristianos, sino, más aún, católico-romanos: de donde el auge en el Seiscientos hispano de la festividad del Corpus Christi, de la devoción a los santos, la Inmaculada Concepción, etc., y con todo ello, de unos repertorios musicales -los villancicos religiosos, con sus temáticas y advocaciones-bien diferenciados. Sin duda, el encargo de este "símbolo de la fe católica", se encaminaba también en esta misma línea de reafirmación religiosa, al tiempo que servía de "advertencia" de los peligros frente a otras opciones, consideradas heréticas: "Quicumque vult salvus esse, ante omnia opus est, ut teneat catholicam fidem...". De ello nos da testimonio también la inserción (junto al libro que anota el "Quicumque", y también junto a todos y cada uno de los libretes conservados) de una segunda carta impresa, que constituye un libelo sobre la música de comedias y la no-licitud de su interpretación en el templo, síntoma evidente de que la inclusión de este tipo de música dramática (profana o no) era en las iglesias españolas algo que se realizaba en la práctica, y que las autoridades eclesiásticas querían atajar, lo que de este modo se recuerda o advierte a los cantores, precisamente aquí, en una obra tan importante como el credo.

7. En realidad, bajo la signatura LS-19 se recoge todo un corpus documental (un libro en copia "de archivo", doce libretes, varios ejemplares impresos de dos cartas alusivas al texto y música de la obra en cuestión, varios documentos manuscritos sobre fundaciones abiertas para costear a perpetuidad la interpretación de la obra y el modo en que ésta debía llevarse a cabo, etc.), el cual constituye un "pequeño tratado" sobre lo que los compositores y músicos prácticos españoles de mediados del siglo XVII conocían sobre el modo de "simbolizar" lo expresado por el texto mediante la música. Un material excepcional para el estudio de las relaciones música-texto (pues el propio compositor nos indica en la primera carta cómo ha querido simbolizar el contenido conceptual del texto en su musicalización). El libro, manuscrito de $35 \times 25 \mathrm{~cm}$., consta de 94 folios numerados; presenta tapas y ataduras de pergamino y páginas de papel; tras el folio 94 aparece un escrito del racionero Juan de Arruego (el encargante de la obra) sobre la constitución de una fundación económica para la interpretación del "Quicumque", y tras él se cosen sendas cartas impresas (Copia de carta que escrivio el licenciado Vrban de Bargas..." (6 pp.) y En la apologia del Doctor Ivan Perez de Montalvan... (4 pp.). Sobre este corpus documental, véase: -Antonio Ezquerro: La música vocal en Aragón en el segundo tercio del siglo XVII. (Tipologías, técnicas de composición, estilo y relación música-texto en las composiciones de las catedrales de Zaragoza).5 vols. Tesis doctoral, Universitat Autònoma de Barcelona, 1997. [El volumen tercero está dedicado a la transcripción en partitura y notación actualizada de la musicalización polifónica de Vargas].

8. El libro distribuye sus folios del siguiente modo: Coro I: Tiple $1^{\circ}$, folios 1-6; Tenor, folios $9-14$; Tiple $2^{\circ}$, folios 17-22. / Órgano: folios 25-31. / Coro II: Tiple, 33-38; Tenor, 41-46; Alto, 49-54; Bajo, 57-62. / Coro III: Tiple, 65-70; Tenor, 73-77; Alto, 79-83; Bajo, 87-92. [El coro primero "simboliza" la Santísima Trinidad, de suerte que el Tenor hace al Padre, el Tiple $1^{\circ}$ al Hijo, y el Tiple $2^{\circ}$ al Espíritu Santo]. 
se puede controlar todo el edificio sonoro. ¿Papeles sueltos o partes sueltas? Tampoco, dado que el material se halla encuadernado y dispuesto así intencionadamente, reuniendo "todo" lo que ha de sonar en un mismo libro (todas las partes vocales e instrumentales), e incluso separando unas voces de otras para que quede bien claro su carácter independiente. ¿Libretes? Tampoco, dado que ya existe un juego de doce libretes independientes, uno para cada parte vocal e instrumental, y aquí, en el libro, tenemos una sola obra, en un único volumen. Y tampoco contamos con una escritura a la manera de los cantorales (con los que por otra parte podría relacionarse esta obra), en disposición de atril...

La intención del libro, pues, parece clara. Se quería dar importancia a esta composición (la que ya en sí tenía, como Credo, ahora "recordada" -reparemos en que se trata de un encargo-, junto al deseo de reforzarla litúrgica y conceptualmente), y de este modo se facilitaba la copia de libretes cuando éstos quedaran desgastados o inservibles por el uso, como así debió suceder". Un texto del calado teológico del "símbolo" no debía dejar lugar -y debía garantizarlo aun con el paso del tiempo- a intromisiones, variantes o modificaciones, por mínimas que éstas fueran. Y así, la existencia de una copia "de archivo" (de 1651-1652) habría asegurado el que, cuando se hubiera precisado sacar nuevas copias de libretes para su uso en años posteriores, los copistas no hubieran introducido ni la más mínima variante, ni, incluso, pequeñas modificaciones propias de los nuevos gustos de su tiempo, como normalmente era lo habitual en copias manuscritas de obras de épocas pasadas (inclusión de alteraciones accidentales, cambio de algunos pasajes, oppures, etc.). Se garantizaba así la estricta permanencia e inmutabilidad del texto original, entonces erróneamente atribuido a San Atanasio.

9. De los doces libretes también conservados (formando cuadernillos, cada uno de $25 \times 17,5 \mathrm{~cm}$. Y diez hojas), varios son de la misma época original, aunque otros fueron copiados a posteriori; todos se ven muy utilizados y gastados por el uso; incluso hay constancia de que la obra se llegó a interpretar, muy posiblemente y de manera excepcional de forma ininterrumpida, hasta entrado el siglo XX. 


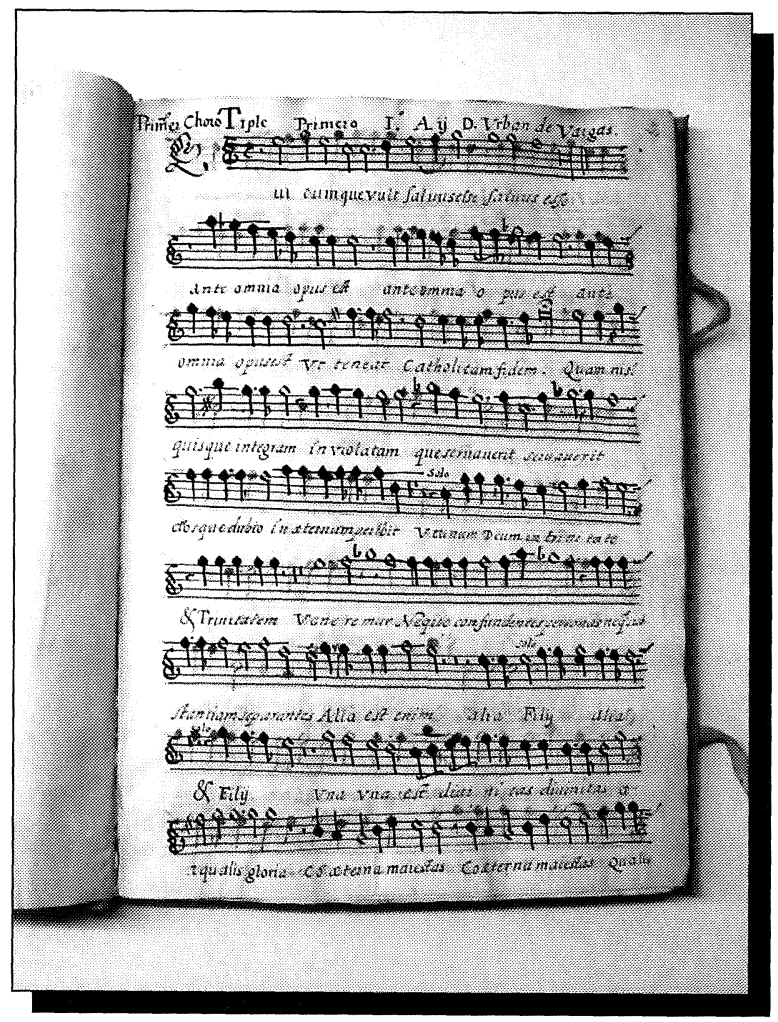

Figura 1 [Quicumque Fol.2r (Tiple $\left.\left.1^{\circ}\right)\right]^{10}$

2.- Música anotada en la correspondencia epistolar entre diferentes maestros de capilla. Conocemos también cómo era habitual en el Seiscientos hispano el intercambio de materiales entre maestros de capilla, con vistas a salvar la obligación que tenían de componer obras nuevas en lengua vernácula para cada ocasión festiva. Esta práctica fue el origen de múltiples re-elaboraciones, adaptaciones, etc., que llegaban a manos de los interesados a través de su correspondencia por carta, enviada por las postas del correo a caballo entonces utilizado. Sólo en el archivo de música de las catedrales de Zaragoza se recogen hasta ciento diez documentos de este tipo, de los cuales sesenta y uno recogen música y el resto intercambio de textos de villancicos y composiciones poéticas y otro tipo de materiales ${ }^{11}$.

En los casos - naturalmente, siempre manuscritos- en que estas cartas incluyen música, ésta se anota de las formas más diversas, aunque, por lo general, atendiendo al siguiente esquema simplificado: el papel de la carta se doblaba en varias partes (habitualmente nueve), de modo que al final el folio de la carta quedara reducido de tamaño a uno de esos pequeños pliegues, donde se anotaba el "sobreescrito" o nombre y dirección del destinatario.

10. Todas las ilustraciones de este artículo se han tomado de los fondos del siglo XVII del archivo de música de las catedrales de Zaragoza.

11. Vid.: -Antonio Ezquerro Esteban, y Luis Antonio González Marín: "Catálogo del fondo documental del siglo XVII del archivo musical de las catedrales de Zaragoza (E: Zac)", en Anuario Musical, 46 (1991), pp. 127-171). 

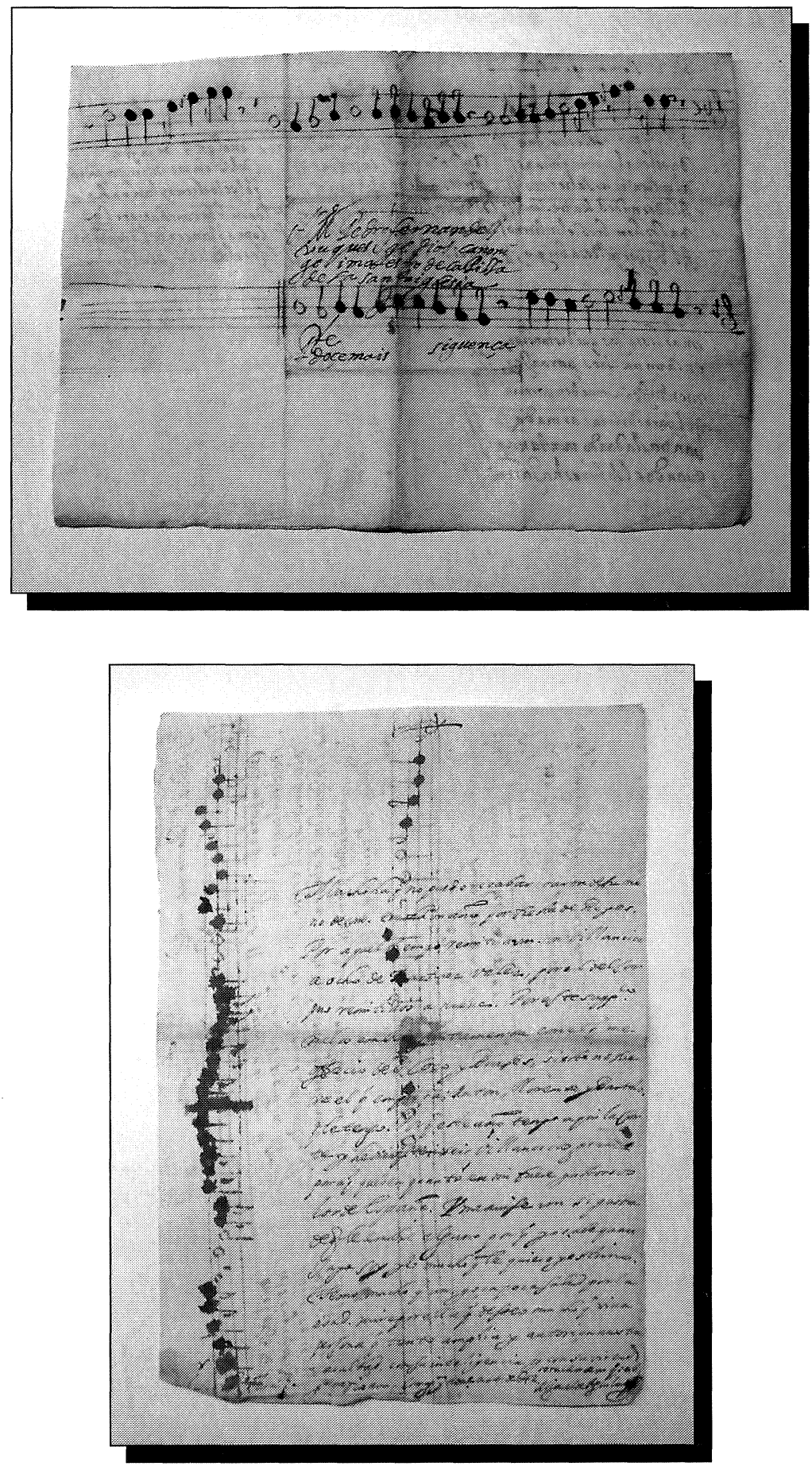

Figuras 2 y 3 [B-59/860, 2v, sobreescrito; y $1 v$, carta del maestro Miguel de Aguilar] 
Seguramente, las cartas irían atadas, aunque no queda constancia de restos de lacre u otro tipo de ligamen. Una vez desplegada y abierta la carta, en la cara del folio donde se anotaba el sobreescrito, podía no haber nada anotado, o bien, en el resto de los pliegues (que no quedarían a la vista estando plegada la carta), se podía anotar el contenido de la carta en cuestión (a menudo, de índole personal, familiar o profesional entre los dos músicos corresponsales), textos poéticos de villancicos, íncipits musicales, temas o tonadas a solo sobre las que poder trabajar, etc.
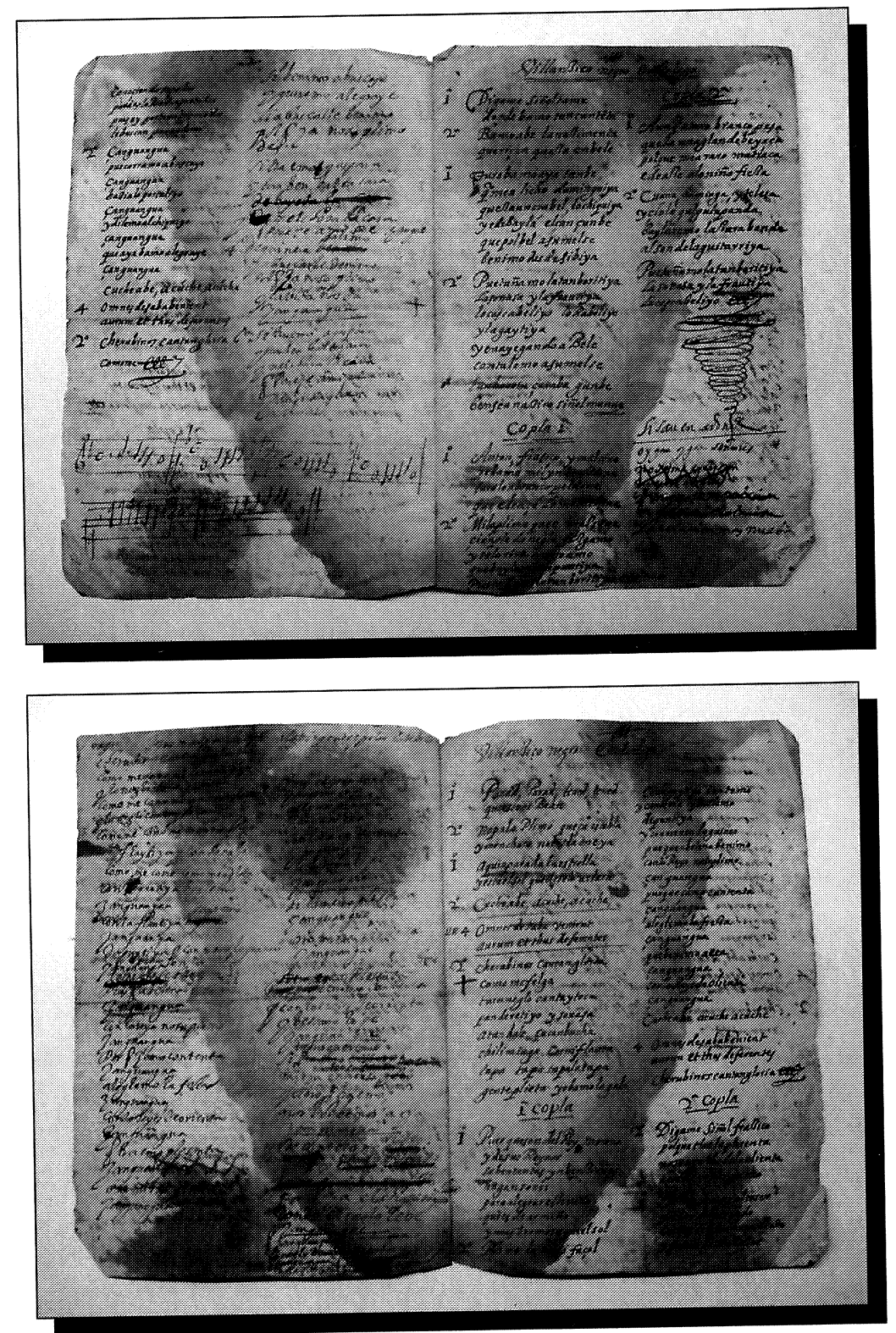

Figuras 4 y 5 [Legajo CXVI, 35r, poesías e incipits musicales, y 35v] 
Todo ello, anotado en las direcciones más variadas, según los pliegues resultantes del papel. Mientras que, por la otra cara del folio, solía anotarse el contenido de la carta, así como, en ocasiones, los mismos materiales poéticos y/o musicales, además de poder incluirse ejemplos completos en partitura o "borrador", con indicaciones de reparto, orden de ejecución de la obra musical, etc.
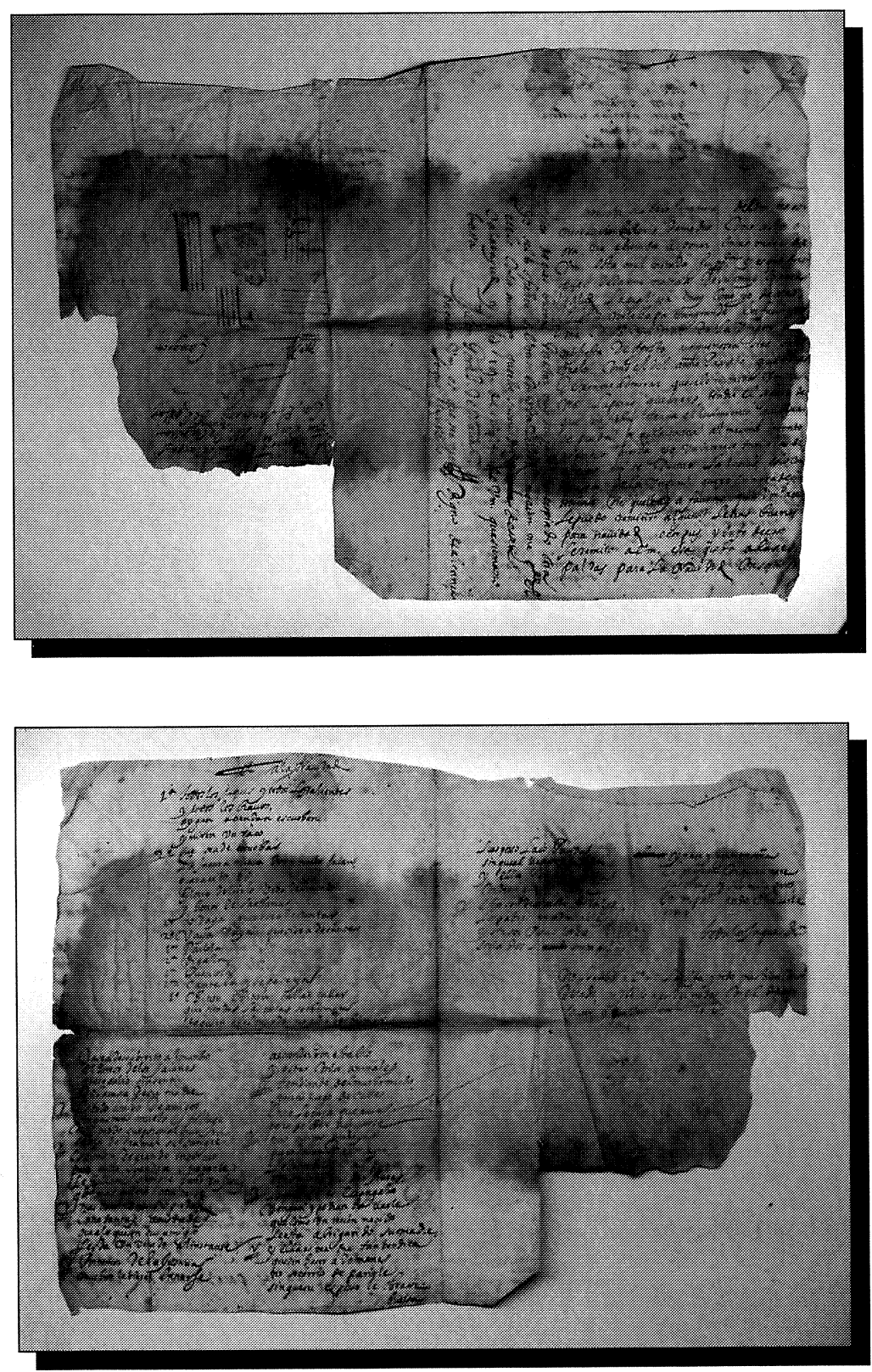

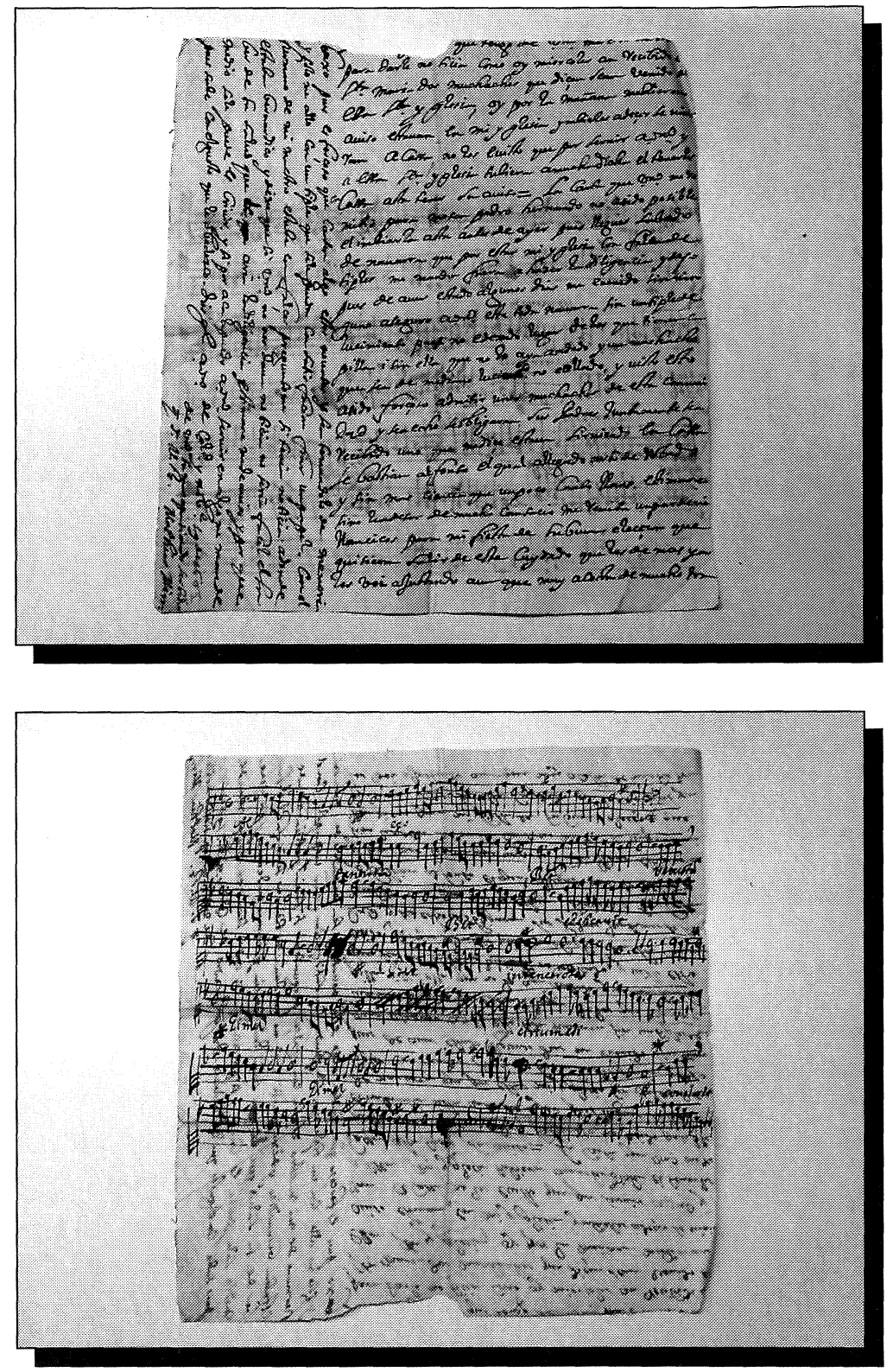

Figuras 6, 7, 8 y 9 [Legajo CXVI, 13r, carta, y 13v, poesías; $y$ B-89/1340 maestro Matías Mira r., carta, y v., música]

El resultado, al analizarlo hoy día en el archivo, son una serie de papeles, algunos de ellos llenos de pliegues, con las formas más peregrinas (en ocasiones, se han cortado o han desaparecido algunos de los dobleces de la carta, acaso porque contenían materiales a re-elaborar, que el destinatario pudiera haber querido separar de la carta para trabajarlos más cómodamen- 
te), y con una escritura anotada en varias direcciones (boca arriba, al revés, con anotaciones en diferentes márgenes, tachaduras...). Unos materiales, que en ocasiones también pueden suponer obras musicales completas, muchas veces sólo así conservadas, realmente complejos de catalogar.
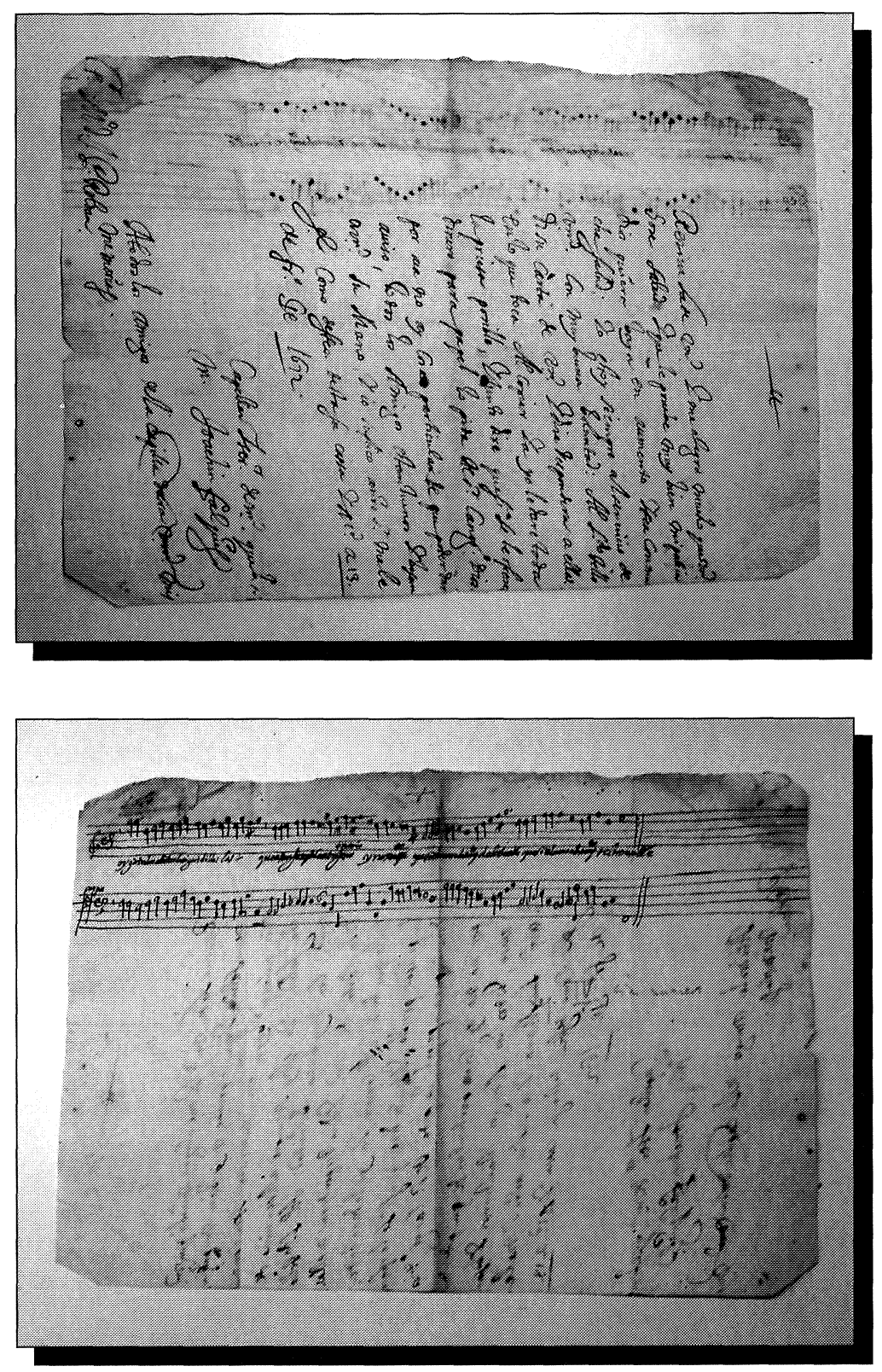

Figuras 10 y 11 [B-94/1423r, carta, y v., música] 
3.- Papeles sueltos agrupando coros completos. Es el caso de la composición en lengua castellana del maestro [Juan de] Torres del mismo archivo zaragozano, ¡Fuera!, que va de invención, a 8 voces, del año 1654 (E: Zac, B-62/890) ${ }^{12}$, la cual, aunque estructurada de modo semejante a muchos villancicos (con un romance a solo a modo de entrada, un estribillo o responsión en el que interviene el tutti, y unas coplas), recoge un baile de disfraces nocturno, o "máscara", de carácter muy posiblemente escénico. La obra (ni partitura, ni papeles sueltos para cada parte vocal o instrumental), se copia manuscrita, únicamente en dos papeles, de 21,4 x 30,8 cm. El primero de ellos reúne las ocho voces, que se copian de corrido una a continuación de otra por ambos lados del papel, de forma que se anota, en la primera y segunda pautas, la responsión del Tiple $1^{\circ}$ del Coro $1^{\circ}$, y acto seguido, en la misma segunda pauta (y siguiendo hasta la tercera), sus coplas; en la cuarta y quinta pautas se copia la responsión del Tiple $2^{\circ}$, y seguidamente se anotan sus coplas (que continúan en la sexta pauta); y así, sucesivamente. No se copian todos los textos (a la manera, rápida, seguramente motivada por su inmediatez práctica, en que se hace en muchas partituras conservadas o "borradores" sobre papel), sino que únicamente se anotan en la voz o voces en que es estrictamente necesario, bien por realizar un solo o un pasaje exclusivo de la parte copiada en cuestión, bien por proceder la obra en dicho lugar contrapuntísticamente en lugar de la más frecuente escritura homófona. En el segundo papel de que se compone el manuscrito original, se copia, por una de sus caras (y por una segunda mano) la parte vocal del romance a solo con sus textos correspondientes, y bajo él, anota el acompañamiento a la responsión (el mismo copista que anotaba en el primer papel las ocho voces); aún más abajo, se anota (el mismo segundo copista que escribía el romance), tachado, aunque legible, el acompañamiento a las coplas, aunque no concuerda armónicamente con ellas (razón por la que sin duda se ha tachado). Y en la zona inferior de la misma cara de papel, se anotan (por el primer copista) los acompañamientos respectivos a las cuatro coplas. Por último, en la otra cara del segundo papel se anotan, exclusivamente, los textos de las ocho coplas, agrupándolos y ordenándolos por voces (Tiple $1^{\circ}$, coplas $1^{\mathrm{a}}$ y $5^{\mathrm{a}}$; Alto, coplas $2^{\mathrm{a}}$ y $6^{\mathrm{a}}$; Tiple $2^{\mathrm{o}}$, coplas $3^{\mathrm{a}}$ y $7^{\mathrm{a}}$; y Tenor, coplas $4^{\mathrm{a}}$ y $8^{\mathrm{a}}$ ). En cualquier caso, nos encontramos ante un modo de copia excepcional en un archivo eclesiástico. Acaso respondiera a una copia "resumida" o a modo de borrador, orden o "guión" de la obra en su conjunto, con vistas a una hipotética "representación", lo que habría originado una copia cómoda (sólo en dos papeles, aunque incluyendo todo el material), su escritura "corrida" (con vistas a sacar más tarde las preceptivas partes en papeles sueltos para cada voz e instrumento), el acompañamiento tachado (acaso por haberse modificado a posteriori), los textos copiados aparte (para aplicar luego la composición poética a la melodía de cada voz), etc., en un procedimento de copia que posiblemente se hubiera empleado con finalidades prácticas en un ámbito escénico-teatral (¿para su fácil manejo entre los músicos de las compañías?), y que en todo caso resulta cercano o a medio camino respecto al antes comentado procedimiento de copia en el caso de las partituras anotadas en tabula compositoria (sobre tabla, y también en los borradores o "borrones" sobre papel).

12. Véase su transcripción a partitura en notación actual y algunos breves comentarios en: -Antonio Ezquerro Esteban: Villancicos policorales aragoneses del siglo XVII. Barcelona, "Monumentos de la Música Española, LIX", CSIC, 2000, pp.161-176, 20-21 (25-26), y 12. 
Pero no se trata éste de un caso aislado: otras composiciones policorales de la misma época, conservadas en el mismo archivo catedralicio de Zaragoza, recogen también papeles de gran formato (doble folio), en donde se copian todas las voces de un coro (a veces más) en un solo papel, unas a continuación de otras, de modo que tenemos los tres coros que componen dicha obra anotados en tan sólo dos o tres papeles.
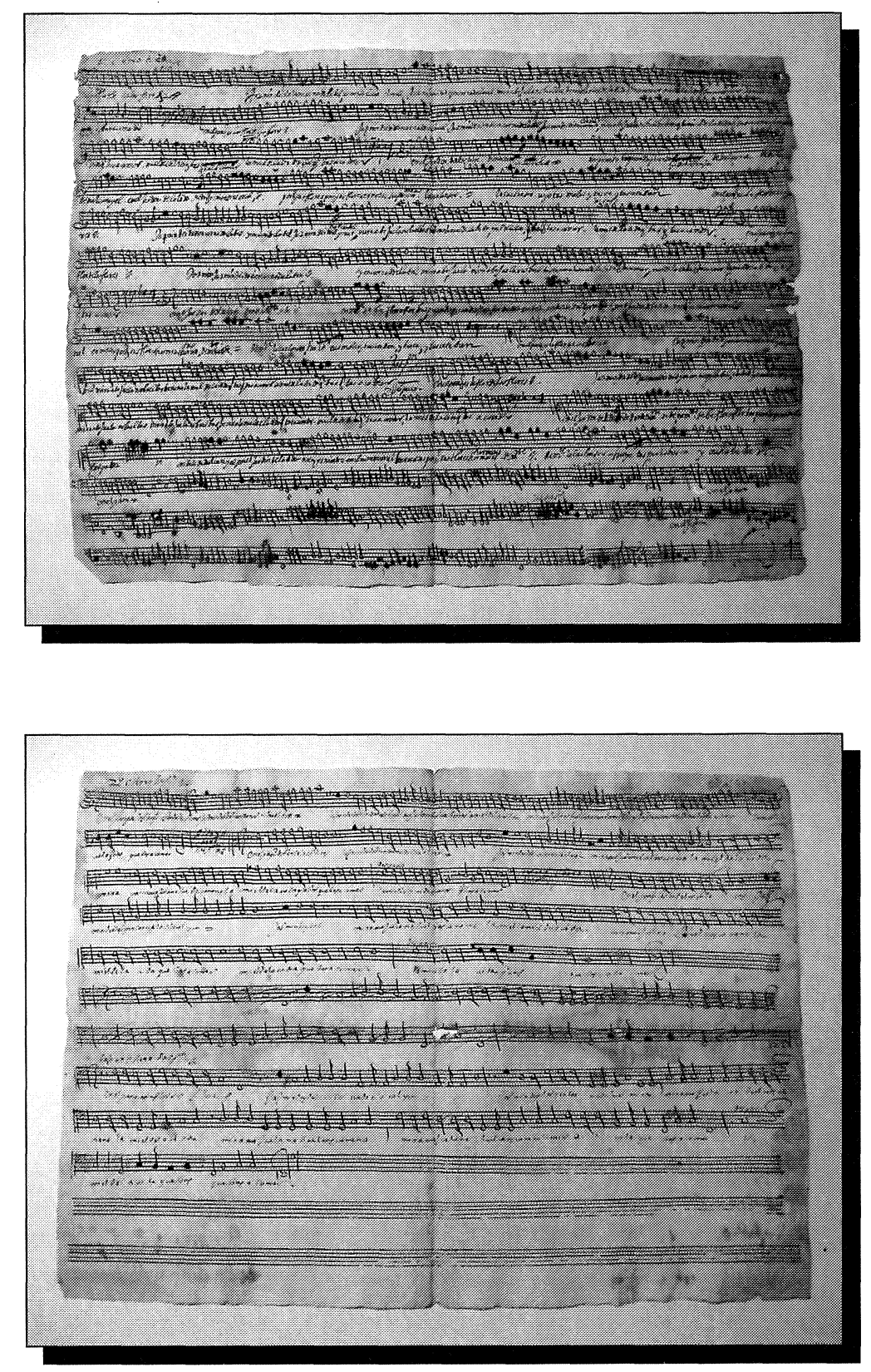

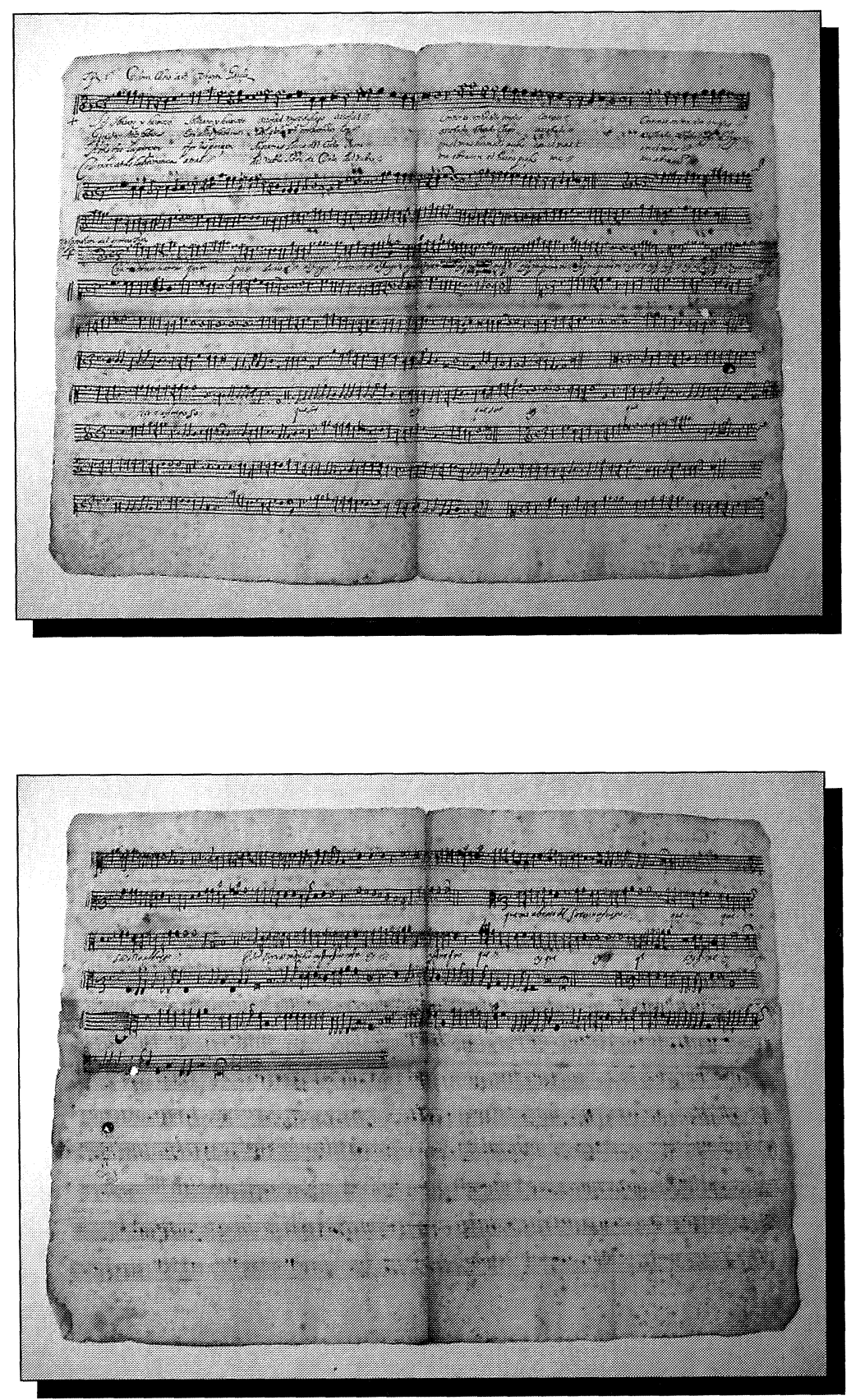


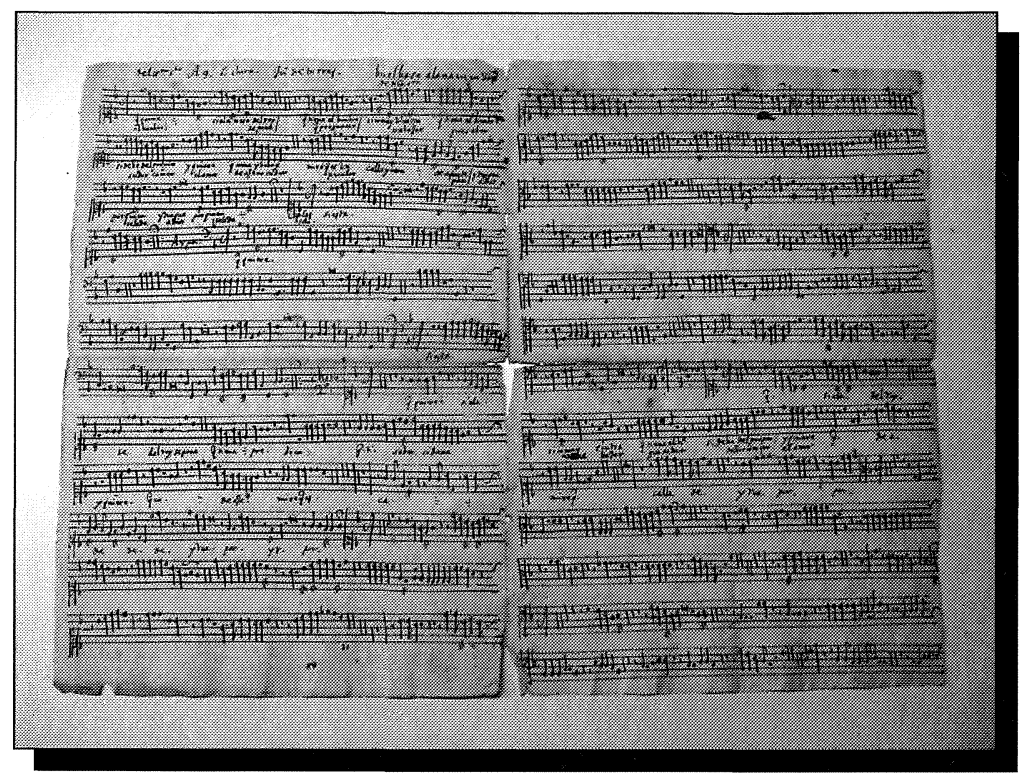

Figuras 12, 13, 14, 15 y 16

[B-30/482, Bernardo del Río, "En el pan que es la flor de las flores", a 8; Hoja 1, coro 1, y Hoja 2, coro 2; B-38/603, Vicente García, "Sol soberano y hermoso", a 8; r, y v.; y B-10/205, Juan de Torres, “¿Qué quiere el hombre?”, a 9].

Es obvio que el modo de copiar la música, en toda época y lugar, ha dependido de algunos factores determinantes, como por ejemplo, el carácter del mecenas encargante de la composición (1), o la función o contexto para el que estuviera concebida la obra musical en cuestión (2). Y en el caso español, estos factores iban a ser muy concretos y diferentes al de otros lugares del mundo occidental.

1.- En primer lugar, porque, en los territorios bajo el dominio de la Corona española -incluidos, naturalmente, los americanos-, el mecenas principal, mayoritario, fue la Iglesia católica. Mientras otras naciones europeas se veían mezcladas en continuas guerras de religión, la uniformidad religiosa de la península ibérica y los nuevos territorios descubiertos era prácticamente absoluta. A ello contribuían los hechos de la expulsión de los judíos realizada en 1492 por parte de los Reyes Católicos, la expulsión de los moriscos decretada en 1610, o el control y rechazo de las nuevas ideas erasmistas llevada a cabo con celo por el Tribunal de la Inquisición, valedor de la nueva "Contrarreforma". De modo que casi la totalidad de la población hispánica profesaba desde principios del siglo XVII la religión católica (lo que iba a perdurar hasta finales del siglo XX), cuyas instituciones regirían toda la vida religiosa, cultural, y en buena parte social del país. Algo básicamente distinto a lo que podía suceder en Italia o Alemania, donde la com- 
partimentación del territorio en pequeños estados gobernados por pequeños príncipes, duques u otros altos dignatarios de la nobleza, aparejaba la necesidad de una música de carácter más privado o personal, con la que ensalzar la grandeza de sus mecenas respectivos, en la mayoría de los casos de carácter civil. En cambio, la cultura musical española, siguiendo una tradición que venía desde la Edad Media, aunque nuevamente impulsada y orientada desde el concilio tridentino, se va a diseminar por todo el territorio a partir de infinitas capillas musicales bajo titularidad eclesiástica. Cada catedral española (en torno a ochenta, sólo en territorio peninsular) disponía de su capilla musical, como asimismo cada colegiata (y siempre hubo más colegiatas que catedrales), cada iglesia parroquial de cierta importancia o influencia en los territorios de su entorno, cada monasterio (El Escorial, Montserrat...), cada convento (Las Descalzas Reales, La Encarnación...), etc. etc. A lo que aún cabría añadir, como en otros países, las diversas capillas musicales de la nobleza (del Duque de Alba, de Su Alteza Don Juan de Austria...), y determinadas colecciones privadas y civiles. Pero el sustrato principal en el cultivo y producción musical hispánico fue, sin duda, la Iglesia católica. Ello condicionó lógicamente los repertorios, las formaciones músicas, las prácticas de las capillas, y un sinnúmero de actividades propias, diferenciadas numerosas veces de las actividades habituales en las capillas musicales civiles o privadas.

2.- La música que precisaba una capilla eclesiástica estaba fundamentada en la solemnización de la liturgia. Es decir, suponía un repertorio en el que las misas, partes del Oficio divino, vísperas, salmos, lamentaciones, motetes, himnos, antífonas, etc., ocupaban el centro de la actividad compositiva de un músico. Para ello se le contrataba y pagaba. De modo que el maestro de capilla debía "cubrir" el calendario litúrgico con una serie variada de composiciones, naturalmente en latín por ser el idioma oficial emanado desde Roma. Pero a partir del siglo XVII, las preferencias por el Ordinario habían ido desplazando paulatinamente a las anteriores por el Propio de la Misa. Así, un maestro debía procurarse un juego más o menos completo de piezas -aunque se trataba de un número relativamente reducido- para utilizar a lo largo del año, puesto que muchas de esas composiciones (las del Ordinario, como las Misas) se podrían utilizar repetidas veces durante el año. De suerte que con unas pocas Misas, composiciones para el Oficio de difuntos (un Requiem, algunos responsos...), para la Semana Santa (un juego de lamentaciones...), y poco más (algunos motetes, secuencias, etc.), un compositor se encontraba en condiciones de ofertar su trabajo a una iglesia para el resto de sus días ${ }^{13}$.

Sin embargo, en el ámbito hispánico, desde finales del siglo XVI (aunque empalmando con tradiciones medievales nunca desaparecidas a pesar de las prohibiciones, como los dramas litúrgicos), había proliferado con gran éxito la ejecución de composiciones musicales en lengua vernácula -los célebres villancicos- en el marco de las festividades más alegres del calendario litúrgico católico-romano. Así por ejemplo, en días como Navidad, Epifanía, o el Corpus Christi, se sustituían los anteriores responsorios de maitines (o se yuxtaponían a ellos, cuestión hoy en

13. Aquí, es preciso tener en cuenta que una capilla de música no actuaba durante todos los días del año -para eso estaba la schola gregoriana-, sino únicamente en determinadas festividades importantes, entre las cuales, además, el maestro de capilla, si así lo consideraba oportuno, podía echar mano del "repertorio" disponible en el archivo catedralicio (p.ej., de obras "clásicas" de facistol de grandes maestros como Josquin, Palestrina, Morales o Victoria) 
abierto debate musicológico), por villancicos o chanzonetas en castellano. Naturalmente, en una sociedad en la que buena parte de la población no sólo desconocía ya para entonces la lengua latina, sino que era además analfabeta, la introducción de música con textos en castellano suponía un elemento de atracción al templo importante. De suerte que al principio, la inclusión de este tipo de piezas fue abiertamente condenado (conocida es la prohibición de Felipe II en este sentido), aunque después, visto su éxito, llegó a ser "tolerada" o permitida, para, al poco, ser francamente fomentada desde las propias autoridades eclesiásticas. Lógicamente, la presencia de villancicos no era algo cotidiano, a ofertar todos los días, sino que quedaba circunscrita, como ya he adelantado, a las fiestas más importantes y alegres del calendario, en las que se buscaba una mayor afluencia -e implicación- de fieles a la iglesia. De manera que la mayor atracción de estas obras procedía de su capacidad de "novedad", de causar sorpresa o asombro en la audiencia. Por ello, los propios cabildos catedralicios se cuidaron repetidamente de exigir a sus maestros de capilla que escribieran, además de las composiciones imprescindibles para solemnizar la liturgia, villancicos "nuevos" para cada ocasión. Esto conllevaba múltiples ventajas e inconvenientes. Como ventajas, impulsaba la "creación" musical, y obligaba a los maestros a experimentar con nuevos procedimientos musicales y textuales en busca de la pretendida novedad y sorpresa a causar en el público. Como inconvenientes, aportaba un carácter "efímero" a esta música, -una música "del momento"-, que en numerosas ocasiones se interpretaba una sola vez, tras de lo cual ya no se volvía a ejecutar nunca más. Y de ahí un condicionante fundamental de su copia: si la obra iba a durar a lo sumo unos pocos días (los necesarios para su ensayo y ejecución pública), no merecía la pena gastar más de lo imprescindible, en papel, encuadernaciones, imprimir, etc. Se trataba, por tanto, de una música prácticamente "de usar y tirar", que debía cumplir un objetivo: catequizar a una audiencia que estaba ávida de escuchar, en su propia lengua, los ritmos de baile que le eran familiares, los instrumentos que le eran más admirados por su actuación sólo en días señalados (sacabuches, cornetas, bajoncillos...), a través de unos textos muchas veces intencionadamente sencillos para que fueran fácilmente comprensibles (aunque con dobles lecturas en ocasiones complejísimas), tomados del romancero, de piezas profanas vueltas a lo divino por medio de la temática pastoril (cercana a pueblos eminentemente agrícolas y ganaderos, como era lo habitual en la España peninsular del Seiscientos), etc. etc. Se trataba de, en el poco tiempo que duraban por ejemplo unos maitines de Navidad, de conseguir que la audiencia saliera del templo tarareando unas melodías rítmicamente incisivas (casi bailándolas) y repitiendo unos textos "fáciles" -aunque sólo aparentemente- de trasfondo religioso: por ejemplo, el Niño recién nacido que llora de frío en el portal, mientras unos pastorcillos le llevan sus humildes regalos y los ángeles cantan en el cielo. De este modo, el compositor lograba, en breve tiempo, implantar "imágenes" en el cerebro del oyente, reforzadas por unos textos subliminalmente muy complejos (se trataba de hacer fácil lo difícil: de arropar, dándoles sensación de gran sencillez, unos mensajes muy complejos: Dios viene al mundo para salvarnos, ha de sufrir a través del llanto como anticipación de su Pasión posterior para redimirnos del pecado...). Y esto se reforzaba mediante unos textos que se entregaban impresos a la audiencia (más tarde, los fieles se los llevarían a sus casas y podrían hacérselos leer por alguien, podrían memorizarlos, etc.), de manera que, lo que 
se había "escenificado" en breves minutos, se prolongaba indefinidamente en el tiempo, calando así el contenido del mensaje que el maestro de capilla había tenido que transmitir musicalmente. Lo culto (el mensaje), por medio de elementos populares (ritmos de danza, textos con sugerencias para la audiencia: tomados del romancero pero vueltos a lo divino...), se hacía popular (se "extendía" entre los oyentes, que lo aprehendían, repetían, variaban en sus diversiones domésticas, etc.). De modo que, al final del proceso, lo "popular" (el rescoldo que había quedado de todo eso en la audiencia, aunque modificado por el paso del tiempo y las variaciones a que se había sometido, conscientes o inconscientes), era propiamente "culto", en un proceso de ida y vuelta: de lo culto (el mensaje), se llegaba a lo culto (el rescoldo), de la misma manera que, aparentemente, de lo popular (los elementos inicialmente utilizados por el compositor) se llegaba a lo popular (su "extensión" en el tiempo y el espacio a una audiencia indefinidamente amplia y abierta a ese rescoldo). 